(C) The Author(s), 2021. Published by Cambridge University Press on behalf of the Arizona Board of Regents on behalf of the University of Arizona. This is an Open Access article, distributed under the terms of the Creative Commons Attribution licence (http://creativecommons.org/licenses/by/4.0/), which permits unrestricted re-use, distribution, and reproduction in any medium, provided the original work is properly cited.

\title{
5 YEARS OF ION-LASER INTERACTION MASS SPECTROMETRY_STATUS AND PROSPECTS OF ISOBAR SUPPRESSION IN AMS BY LASERS
}

\author{
Martin Martschini*(1) - Johannes Lachner(i) - Karin Hain (1) - Michael Kern (10) \\ Oscar Marchhart (10 - Johanna Pitters • Alfred Priller • Peter Steier(1) - Andreas Wiederin • \\ Alexander Wieser(i) $\bullet$ Robin Golser (D)
}

University of Vienna, Faculty of Physics - Isotope Physics, Waehringer Strasse 17, A-1090 Vienna, Austria

\begin{abstract}
A setup for ion-laser interaction was coupled to the state-of-the-art AMS facility VERA five years ago and its potential and applicability as a new means of isobar suppression in accelerator mass spectrometry (AMS) has since been explored. Laser photodetachment and molecular dissociation processes of anions provide unprecedented isobar suppression factors of $>10^{10}$ for several established AMS isotopes like ${ }^{36} \mathrm{Cl}$ or ${ }^{26} \mathrm{Al}$ and give access to new AMS isotopes like ${ }^{90} \mathrm{Sr},{ }^{135} \mathrm{Cs}$ or ${ }^{182} \mathrm{Hf}$ at a 3-MV-tandem facility. Furthermore, Ion-Laser InterAction Mass Spectrometry has been proven to meet AMS requirements regarding reliability and robustness with a typical reproducibility of results of $3 \%$. The benefits of the technique are in principle available to any AMS machine, irrespective of attainable ion beam energy. Since isobar suppression via this technique is so efficient, there often is no need for any additional element separation in the detection setup and selected nuclides may even become accessible without accelerator at all.
\end{abstract}

KEYWORDS: accelerator mass spectrometry, AMS, Ion-Laser InterAction Mass Spectrometry, isobar suppression, laser photodetatchment.

\section{INTRODUCTION}

The backbone of the outstanding abundance sensitivity of accelerator mass spectrometry (AMS) is its ability to nearly completely suppress isobaric interferences. Given a typical mass resolution of $A M S$ spectrometers of $M / \Delta M \approx 300$, all ion species with the same integer mass as the isotope of interest require suppression in one of the multiple filters of an AMS instrument. Molecular isobars are completely dissociated in the stripping process, by selecting high charge states that lack the electrons for molecular binding or by collisional dissociation in a rather dense stripper medium (Schulze-König et al. 2011). Either way, most fragments are subsequently separated in the high energy spectrometer and only $\mathrm{m} / \mathrm{q}$ ambiguities of the isotope of interest can reach the detection setup, albeit at a different, typically lower charge state and thus different kinetic energy (Kilius et al. 1997). Provided that their intensities do not overload the detection setup, they can be fully separated by total energy detection. For several AMS isotopes like ${ }^{14} \mathrm{C},{ }^{26} \mathrm{Al},{ }^{55} \mathrm{Fe}$ or ${ }^{129} \mathrm{I}$, this is sufficient for a background-free identification of the isotope of interest as no anions of these atomic isobars exist.

The majority of long-lived radioisotopes, however, have at least one abundant stable atomic isobar with the ability to form negative ions. The capabilities of sample preparation chemistry in isobar reduction typically end at the $0.1-1 \mathrm{ppm}$ level, thus detection levels of $10^{-12}-10^{-15}$ are only achievably with instrumental isobar suppression by many orders of magnitude. While a favorable choice of the anion species from the ion source (hydrides, oxides, fluorides) may partly accomplish this (e.g., Raisbeck et al. 1981; Vockenhuber et al. 2004), isobar suppression typically relies on nuclear physics means in the detection setup: differential energy loss, gasfilled-magnets, degrader or absorber foils or full stripping. All of these techniques have in common that their performance increases with kinetic energy or velocity of the ions and that

\footnotetext{
*Corresponding author. Email: martin.martschini@univie.ac.at
} 
they become less efficient the smaller the relative difference in atomic number between isotope of interest and isobar, i.e., for high Z-nuclides (for an overview, see Synal 2013). While ${ }^{10} \mathrm{Be}-{ }^{10} \mathrm{~B}$ can nowadays be sufficiently separated at $720 \mathrm{keV}$ kinetic energy from a $300 \mathrm{kV}$ tandem (Maxeiner et al. 2019), ${ }^{60} \mathrm{Fe}-{ }^{60} \mathrm{Ni}$ already requires $>110 \mathrm{MeV}$ from a $>11 \mathrm{MV}$ tandem (Ludwig et al. 2016; Wallner et al. 2016) and ${ }^{81} \mathrm{Kr}^{81} \mathrm{Br}$ could only be separated to the ${ }^{81} \mathrm{Kr} / \mathrm{Kr}$ level of $10^{-13}$ at $3.6 \mathrm{GeV}$ kinetic energy from a cyclotron (Collon et al. 2000). Given the vast part of the nuclear chart that cannot be accessed by these techniques (cf. Figure 2) and the progressing scarcity of large tandem facilities, alternative techniques for isobar suppression independent of attainable particle energy have come into focus. Ideally, they may enable measurement of a range of radionuclides at compact AMS facilities now dedicated to radiocarbon only or even dispensing the accelerator-A from AMS.

The idea to exploit differences in electron affinities (EA) for isobar suppression of anions by laser photodetachment has been explored from the early days of AMS (Berkovits et al. 1989), however it took another 20 years of development to attain sufficient continuous isobar depletion by extending ion-laser interaction times to $\mathrm{ms}$ in a linear radiofrequencyquadrupole (RFQ)-ion guide (Liu et al. 2005; Andersson et al. 2010). In 2016, the first IonLaser InterAction Mass Spectrometry (ILIAMS) setup based on this principle was coupled to the state-of-the-art 3-MV-AMS facility VERA (Vienna Environmental Research Accelerator) (Steier et al. 2004; Golser et al. 2017). After 5 years of successful operation, it's time for a review of this technique, its achievements, and its potential.

\section{The ILIAMS-Technique_-Advantages and Challenges}

The layout of the ILIAMS setup including a schematic of VERA is shown in Figure 1 and detailed descriptions are given in Martschini et al. (2017, 2019), the essentials are repeated briefly here. Negative ions from a Multicathode-SNICS ion source are accelerated to $30 \mathrm{keV}$ energy and mass-analyzed with a $90^{\circ}$ bending magnet. Next, the ion beam is electrostatically decelerated to $30-60 \mathrm{eV}$ by a high voltage platform and enters a 1-m-long RFQ-ion guide mounted there. Being filled with buffer gas, typically $\mathrm{He}$ at pressures of 3-5 Pa, it serves as an ion cooler and further thermalizes the ion beam to kinetic energies lower than $1 \mathrm{eV}$. Inside the cooler, the ion beam is collinearly overlapped with an intense laser beam with a photon flux of $\sim 5 \times 10^{20} \mathrm{~cm}^{-2} \mathrm{~s}^{-1}$. Owing to ion-laser interaction times on the order of ms inside the cooler (Martschini et al. 2017), ion species with EAs below the photon energy are efficiently neutralized by photodetachment, i.e., $>99.99 \%$, despite low cross sections on the order of $10^{-17} \mathrm{~cm}^{2}$ for this non-resonant process. At the same time, anions with EAs higher than the photon energy stay unaffected. All surviving anions are reaccelerated to $30 \mathrm{keV}$ upon leaving the high voltage platform, energy analyzed by an ESA and transported to the AMS instrument, where another mass filter needs to be passed before injection into the tandem. Since the degree of suppression does not depend on terminal voltage, the ILIAMS-setup can be coupled in principle to any AMS facility.

Differences in EAs or, in case of molecules, in vertical detachment energies (VDE) for isobar pairs are typically at least several tenths of eV (Andersen et al. 1999; Rienstra-Kiracofe et al. 2002) such that commercial lasers of suitable photon energy are usually readily available. Currently, these may either be cw-lasers or pulsed laser with repetition rates above several ten $\mathrm{kHz}$. In case atomic anions have the wrong order of EAs for ILIAMS isobar suppression, a suitable molecular system has to be found to meet the requirements. The proper choice of molecular species sometimes requires tedious experimental work as only 


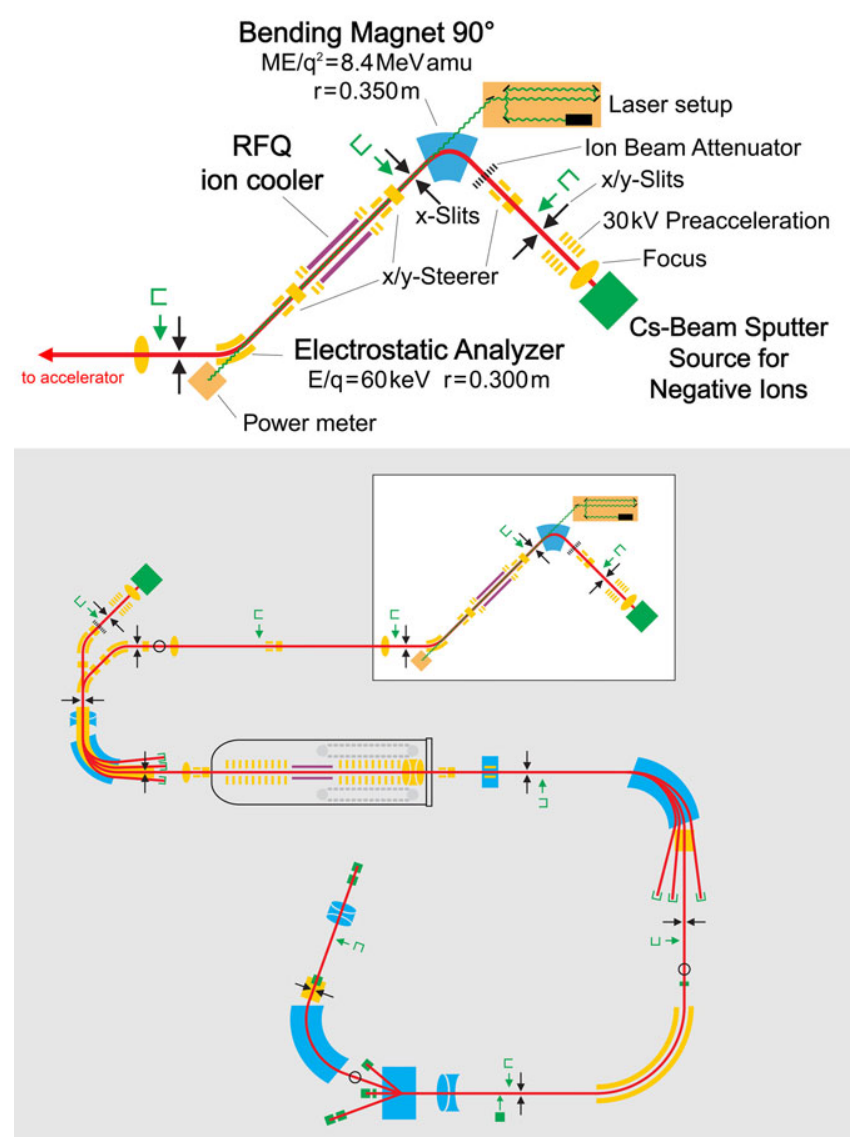

Figure 1 Layout of the ILIAMS setup and its coupling to the VERA AMS facility. Electrostatic components are shown in yellow, magnetic components in blue and components for ion generation and detection in green. (Please see electronic version for color figures.)

scarce data on the EAs or VDEs of prolific molecules like fluorides or oxides is available. In addition, a substantial fraction of molecular ions from a sputter ion source is heavily excited (Gnaser 2007) and may be photodetached at energies substantially lower than their EA or VDE. Thus, EA/VDE differences in molecular situations should be as large as possible to mitigate losses of the anion of interest.

A complimentary technical approach termed Isobar Separator for Anions (ISA) exploits the very same differences in electronic structure for isobar suppression via resonant charge transfer reactions with reactive gases in a similar ion guide (Litherland et al. 2007). Demonstration experiments suggest suppression factors of 5-6 orders of magnitude (Eliades et al. 2010), although no results from full AMS measurements have been published so far. An advantage of the ISA technique is that changing gas is certainly cheaper and quicker than switching to yet another laser for a new isotope. However, ISA isobar suppression seems to be ultimately limited by a plateau effect (Eliades et al. 2015). We observe similar behavior in our setup when running the system without lasers and using reactive gases instead of 
pure He to induce molecular reactions (e.g., $\mathrm{WF}_{5}{ }^{-} \rightarrow \mathrm{WF}_{5} \mathrm{O}^{-}$) $($Martschini et al. 2020). In our interpretation, this plateau effect is determined by the likelihood of reverse reactions when the chemical equilibrium inside the ion cooler is reached. While the stability criterion of an RFQ ion guide typically allows the extra electron to stay in the system when bound to the modified molecule or resonantly transferred to a gas molecule, a free electron detached by lasers has no stable trajectory in the RFQ and is immediately removed from the system to one of the electrodes. Thus, a reverse reaction of the photodetachment process is virtually impossible and no plateau effect has been observed with laser photodetachment, paving the way for isobar suppression factors of $>10^{10}$, i.e., "complete" isobar suppression (see below).

A challenge in AMS context for ion guide techniques is the intensity of the ion beam as RFQion guides typically cannot handle beam currents of several $\mu \mathrm{A}$ or above. In order not to hamper conventional AMS measurements, these ion guides should therefore be either removable or part of a separate injector. Of course, this current limitation also applies to the stable reference isotope during ILIAMS measurements. Even at ion currents of several $100 \mathrm{nA}$, space charge influences both the beam transmission as well as the ion residence time in the system (Martschini et al. 2017, 2019). Consequently, stable reference isotope beams need to be attenuated in a reproducible way conserving as much as possible from the original phase space. At VERA, this is currently accomplished by slow sequential injection of isotopes and pneumatically inserting a perforated metal sheet, i.e., an industrial sieve, into the beam during stable isotope sequences. Typical sequence durations are 100 $250 \mathrm{~s}$ counting on the rare isotope followed by 5-10 s of stable reference isotope injection. The reproducibility of AMS results with this method is around 3\% (Lachner et al. 2019, 2021), which is dominated by an observed inter-target scatter among results from multiple sputter targets of the same sample material rather than the statistical precision (cf. Table 1) or reproducibility on a single sputter target over multiple runs. We attribute this to variations in ion beam loss during injection into the cooler caused by differences in sample cratering and/or a slight eccentricity of the sample wheel. Nonetheless, the present reproducibility meets the requirements for most established AMS nuclides other than ${ }^{14} \mathrm{C}$ and certainly is satisfactory for nuclides previously inaccessible at environmental levels.

\section{STATUS AND PROSPECTS}

In the following, the current experimental situation and prospects of the ILIAMS-technique for several successfully established AMS nuclides as well as some interesting new candidates will be discussed including requirements for their subsequent AMS detection. An overview of nuclides measured with ILIAMS is shown in Figure 2. Results presented below were obtained with one of the three following laser systems: $532 \mathrm{~nm}$ (2.33 eV photon energy, cw, VERDI V18, Coherent Inc.), $355 \mathrm{~nm}$ (3.49 eV, $100 \mathrm{kHz}$ repetition rate, AVIA-LX, Coherent Inc.) $455 \mathrm{~nm}$ (2.72 eV, cw, Spyder Arctic III, Wicked Lasers). Individual events were counted in a split-anode gas ionization chamber (GIC) on the high energy side of VERA (Forstner et al. 2008).

\section{Fully Developed Stage}

ILIAMS is successfully applied in full AMS measurements of these isotopes at VERA, the respective key performance parameters are summarized in Table 1. 
Table 1 Key performance parameters of ILIAMS AMS at VERA for the 4 established isotopes. Values given are averages over various beamtimes in the past and not the best values observed so far.

\begin{tabular}{|c|c|c|c|c|c|c|c|c|c|c|}
\hline $\begin{array}{l}\text { Sample with } \\
\text { isotopic ratio }\end{array}$ & $\begin{array}{l}\text { Injected } \\
\text { ion } \\
\text { species }\end{array}$ & $\begin{array}{l}\text { Ref. } \\
\text { isotope } \\
\text { current }^{(a)} \\
(\mathrm{nA})\end{array}$ & $\begin{array}{l}\text { Terminal } \\
\text { voltage } \\
\text { (MV) }\end{array}$ & $\begin{array}{l}\text { HE } \\
\text { charge } \\
\text { state }\end{array}$ & $\begin{array}{c}\text { Cooler } \\
\text { transmission } \\
(\%)\end{array}$ & $\begin{array}{c}\text { Accelerator } \\
\text { transmission \& } \\
\text { yield }(\%)\end{array}$ & $\begin{array}{c}\mathrm{HE} \\
\text { normalizaton } \\
\text { factor }^{(b)}\end{array}$ & $\begin{array}{l}\text { Rare isotope } \\
\text { counts in } \\
100 \mathrm{~s}^{\text {live }} \\
\text { time }^{(\mathrm{c})}\end{array}$ & $\begin{array}{l}\text { Rare isotope } \\
\text { counts in } \\
10 \text { min } \\
\text { sputtering (d) }\end{array}$ & $\begin{array}{l}\text { Back- } \\
\text { ground }\end{array}$ \\
\hline${ }^{36} \mathrm{Cl} / \mathrm{Cl}=10^{-12}$ & $\mathrm{Cl}^{-}$ & 8000 & 1.75 & $2+$ & 64 & 31 & 0.9 & 1458 & 4065 & $8 \times 10^{-16}$ \\
\hline${ }^{26} \mathrm{Al} / \mathrm{Al}=10^{-12}$ & $\mathrm{AlO}^{-}$ & 1500 & 2.95 & $3+$ & 54 & 28 & 1.0 & 143 & 500 & $5 \times 10^{-16}$ \\
\hline${ }^{90} \mathrm{Sr} / \mathrm{Sr}=10^{-12}$ & $\mathrm{SrF}_{3}^{-}$ & 300 & 3.00 & $3+$ & 35 & 25 & 2.2 & 9 & 27 & $5 \times 10^{-15}$ \\
\hline${ }^{135} \mathrm{Cs} / \mathrm{Cs}=10^{-10}$ & $\mathrm{CsF}_{2}^{-}$ & 70 & 2.65 & $3+$ & 33 & 23 & 2.9 & 115 & 160 & $6 \times 10^{-12}$ \\
\hline
\end{tabular}

(a) Unattenuated reference isotope current in front of the ion cooler, values for $\mathrm{Cl}$ and $\mathrm{Sr}$ are ${ }^{35} \mathrm{Cl}$ and ${ }^{88} \mathrm{Sr}$ resp.

(b) Nominal isotopic ratio divided by the raw measured isotopic ratio. Usually, values are above 1 due to limited ROI acceptance in the detection setup. Values below 1.0 indicate that the transmission of the rare isotope through the system, especially the ion cooler, is higher than for the reference isotope.

${ }^{(c)}$ Rare isotope counts collected within a 100 s long continuous counting sequence.

(d) Rare isotope counts collected within 10 min sputter time in measurement mode considering times lost for reference isotope injection, switching between setups for slow sequential injection, counting of other masses, etc. 


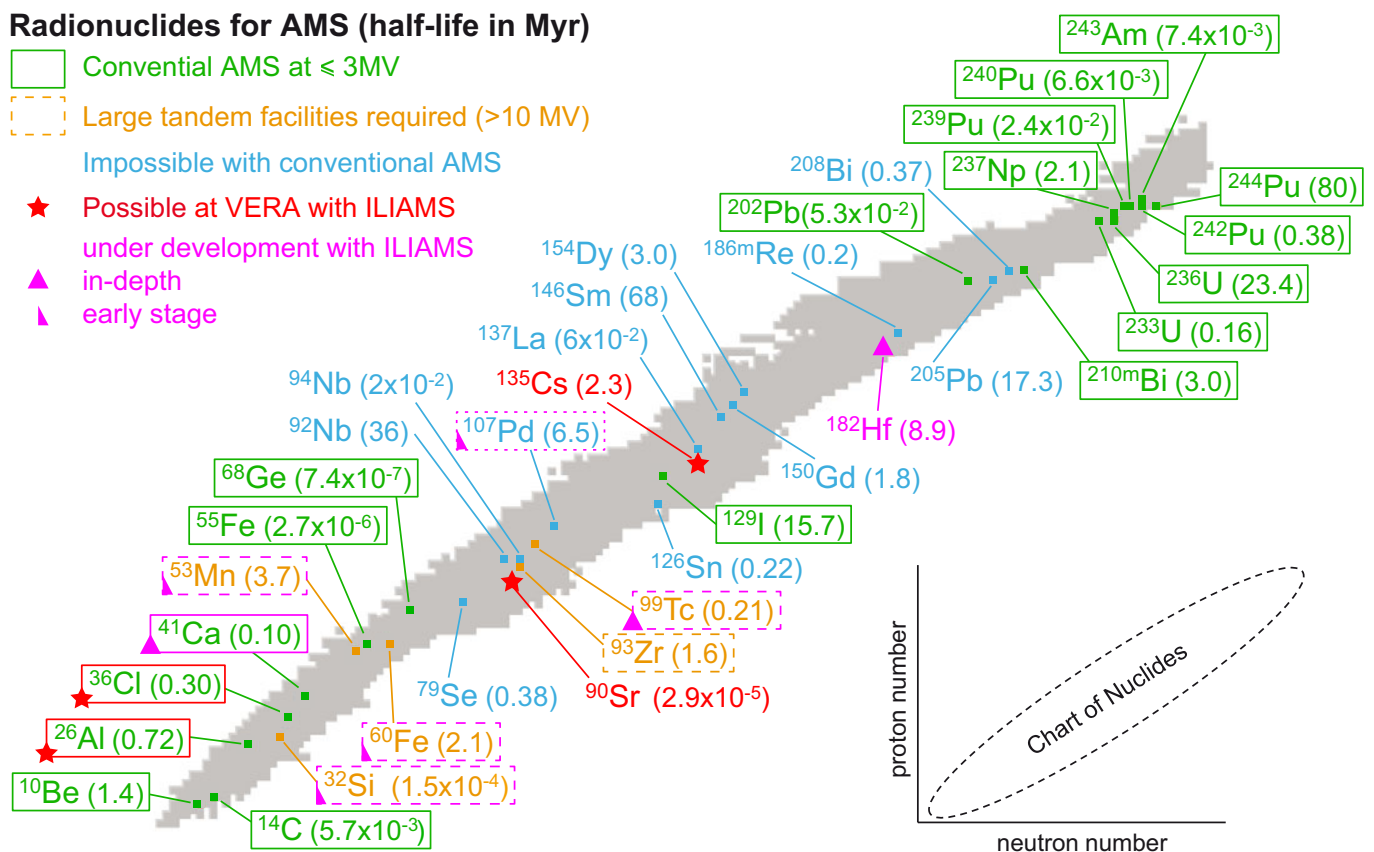

Figure 2 Nuclear chart showing long-lived radionuclides of interest and potential interest for AMS. Nuclides are coded according to their present accessibility with AMS and the development status of ILIAMS. Half-lives in Myr are indicated in the round brackets.

\section{${ }^{36} \mathrm{Cl}$}

With its high EA of $3.6 \mathrm{eV},{ }^{36} \mathrm{Cl}$ is the prototype radionuclide for ILIAMS and is routinely measured with this technique at VERA for 4 years (Lachner et al. 2019). A $532 \mathrm{~nm}$ laser with $10 \mathrm{~W}$ power can reduce the intensity of the isobar ${ }^{36} \mathrm{~S}(\mathrm{EA} 2.1 \mathrm{eV})$ by more than 10 orders of magnitude at an overall ${ }^{36} \mathrm{Cl}$ transmission through the ion guide of up to $80 \%$. This essentially omits the need for any further atomic isobar discrimination and blank values below ${ }^{36} \mathrm{Cl} / \mathrm{Cl}=10^{-15}$ become accessible at beam energies of only $5.4 \mathrm{MeV}$. Sulfurspiked samples demonstrate that this background stems from ${ }^{36} \mathrm{Cl}$ contamination in the ion source and during sample handling and not from isobaric interference, which is several orders of magnitude lower. Using the highly populated $2+$ charge state in the HEspectrometer after the VERA accelerator, no other ion species than ${ }^{36} \mathrm{Cl}^{2+}$ is observed in the GIC. Before stripping in the accelerator, ${ }^{17} \mathrm{O}^{19} \mathrm{~F}^{-}$is typically the only isobaric ion species in the $\mathrm{m}=36$-beam after ILIAMS, all other possible interferences like $\mathrm{O}_{2}{ }^{-}$and $\mathrm{C}_{3}{ }^{-}$ are completely suppressed in the RFQ with $>2 \mathrm{~W}$ of laser power. Since the EA of ${ }^{17} \mathrm{O}^{19} \mathrm{~F}^{-}$ is $2.27 \mathrm{eV}$ (Rienstra-Kiracofe et al. 2002), photons with higher energy (e.g., from the $355 \mathrm{~nm}$ laser) are expected to sufficiently remove also this last interference, which could pave the way for accelerator-free detection of ${ }^{36} \mathrm{Cl}$.

${ }^{26} \mathrm{Al}$

In principle, $\mathrm{AMS}$ of ${ }^{26} \mathrm{Al}$ completely avoids atomic isobars when selecting the elemental anion $\mathrm{Al}^{-}$for injection because $\mathrm{Mg}$ has a negative EA (Andersen et al. 1999). On the other hand, the oxide anion $\mathrm{AlO}^{-}$typically yields 10 times higher ion currents and ionization efficiencies from an $\mathrm{Al}_{2} \mathrm{O}_{3}$ sputter matrix, at the cost of $\mathrm{MgO}^{-}$interference. Fortunately, ILIAMS provides 
unprecedented suppression of $\mathrm{MgO}^{-}$of $>10^{14}$ at $\sim 50 \%$ overall transmission of $\mathrm{AlO}^{-}$through the ion guide and allows to exploit the benefits of higher overall detection efficiency (Lachner et al. 2021). Despite a published VDE of $1.61 \mathrm{eV}$ (Cheng et al. 2013), $\mathrm{MgO}^{-}$is suppressed by up to $10^{5}$ by simple passage through pure $\mathrm{He}$ and ${ }^{16} \mathrm{O}^{-}$is found in the ion beam exiting the cooler. While clearly suggesting dissociation reactions, this behavior is still not fully understood and e.g., not observed for $\mathrm{MnO}^{-}$, a diatomic anion with similar EA (see below). Photons from the $532 \mathrm{~nm}$ laser "completely" remove any remaining $\mathrm{MgO}^{-}$with measured suppression factors of $10^{11}$. Hence, only $\mathrm{m} / \mathrm{q}$-ambiguity-fragments of other molecules may reach the GIC, most notably ${ }^{13} \mathrm{C}^{1+}$ when selecting the $2+$ charge state after the accelerator and may warrant use of the less populated $3+$ charge state for samples with elevated C-content. Even the $1+$ charge state could be an option at compact facilities provided that interference from molecular fragments of ${ }^{10} \mathrm{~B}^{16} \mathrm{O}_{2}{ }^{-},{ }^{13} \mathrm{C}_{2}{ }^{16} \mathrm{O}^{-}$and ${ }^{13} \mathrm{C}^{12} \mathrm{CH}^{16} \mathrm{O}^{-}$can be suppressed either with ILIAMS or in the terminal stripper. The gain in overall detection efficiency with ILIAMS at VERA is $3-5$, which substantially cuts down measurement times. Especially low-level samples benefit from the improved counting statistics and blanks are measured down to ${ }^{26} \mathrm{Al} /{ }^{27} \mathrm{Al}=5 \times 10^{-16}$. This method has become the standard technique for AMS of ${ }^{26} \mathrm{Al}$ at VERA (Lachner et al. 2021).

${ }^{90} \mathrm{Sr}$

The fission product ${ }^{90} \mathrm{Sr}\left(\mathrm{T}_{1 / 2}=28.64\right.$ a) is of high environmental interest both for its radiotoxicity and its potential as a tracer, but conventional AMS detection is complicated by the presence of the isobar ${ }^{90} \mathrm{Zr}$ and, to a lesser extent, ${ }^{90} \mathrm{Y}$. ILIAMS provides a suppression of $\mathrm{ZrF}_{3}^{-}$and $\mathrm{YF}_{3}^{-}$vs. $\mathrm{SrF}_{3}^{-}$of $>10^{7}$ with $12 \mathrm{~W}$ of power from the $532 \mathrm{~nm}$ laser and admixing $3 \%$ of $\mathrm{O}_{2}$ to the $\mathrm{He}$ buffer gas (Martschini et al. in preparation). Interestingly, the degree of suppression by photons or gas alone is 1-2 orders of magnitude lower, which means that the two effects obviously do not multiply. The exact reaction channels have not been studied so far but ISA results support the low stability of $\mathrm{ZrF}_{3}^{-}$ (Eliades et al. 2013, 2015).

Extraction of $\mathrm{SrF}_{3}{ }^{-}$from the ion source and elemental separation in the GIC at $10.85 \mathrm{MeV}$ ion energy ( $3 \mathrm{MV}, 3+$ charge state) provide additional suppression of $\mathrm{Zr}$ of $>10^{5}$. The mean blank value from commercial $\mathrm{SrF}_{2}$ as well as full chemistry blanks from ${ }^{90} \mathrm{Sr}$-free soil is ${ }^{90} \mathrm{Sr} / \mathrm{Sr}=$ $(4.5 \pm 3.2) \times 10^{-15}$ at an overall Sr-detection efficiency of $4 \times 10^{-4}$ and results in a detection limit of $0.08 \mathrm{mBq}$. This corresponds to more than a 30 -fold improvement of previous AMS benchmarks, which were similar to the radiometric limit of $3 \mathrm{mBq}$ (Tumey et al. 2009; Sasa et al. 2021). Studies of ${ }^{90} \mathrm{Sr}$ in environmental samples with ILIAMS have been initiated.

\section{${ }^{135,137} \mathrm{Cs}$}

The radioisotopes ${ }^{135} \mathrm{Cs}\left(\mathrm{T}_{1 / 2}=2 \times 10^{6}\right.$ a) and ${ }^{137} \mathrm{Cs}\left(\mathrm{T}_{1 / 2}=30.17\right.$ a) are produced with high yield in nuclear fission with the latter being a well-established environmental tracer. Gaining access to the isotopic ratio ${ }^{135} \mathrm{Cs} /{ }^{137} \mathrm{Cs}$ would have significant advantage for source identification but AMS detection attempts were rather scarce, both due to isobaric interference from stable Ba-isotopes as well as the challenge posed by the use of Cs in typical AMS sputter ion sources. ISA experiments tackled the first problem and identified $\mathrm{CsF}_{2}^{-}$as a suitable anion species for ion guide techniques (Eliades et al. 2013; MacDonald et al. 2014).

ILIAMS enables the suppression of the isobar $\mathrm{BaF}_{2}^{-}$with the $532 \mathrm{~nm}$ laser by a factor $10^{5}$ against $\mathrm{CsF}_{2}^{-}$at more than $30 \%$ transmission of the $\mathrm{CsF}_{2}^{-}$-beam from the ion source 
through the ILIAMS setup. After the accelerator, the most populated charge state $3+$ is chosen with a stripping yield of $\sim 23 \%$. Anyway, the GIC does not contribute to the elemental discrimination from $\mathrm{Ba}$ and even at a beam energy of $27 \mathrm{MeV}$ (achieved by selecting the sparsely populated $8+$ charge state), Ba ends up in the same spot of the GIC-spectra as Cs. Consequently, the Ba-contribution to the respective Cs-signals has to be inferred from monitoring the count rate of ${ }^{136} \mathrm{Ba}$.

In the ion source, $\mathrm{Rb}$ is used as sputter material and yields $\mathrm{CsF}_{2}{ }^{-}$-beam currents of up to $100 \mathrm{nA}$ from a $\mathrm{Cs}_{2} \mathrm{SO}_{4}+\mathrm{PbF}_{2}+\mathrm{Cu}$ sputter matrix. Typically, $\mathrm{BaF}_{2}^{-}$is fully suppressed and only $\mathrm{Ba}-$ spiked samples show some ${ }^{136} \mathrm{Ba}^{3+}$-events. Blank values measured on commercial $\mathrm{Cs}_{2} \mathrm{SO}_{4}$ presently are ${ }^{137} \mathrm{Cs} /{ }^{133} \mathrm{Cs}=3 \times 10^{-12}$ and ${ }^{135} \mathrm{Cs} /{ }^{133} \mathrm{Cs}=6 \times 10^{-12}$ and represent new AMS benchmarks. Since ${ }^{137} \mathrm{Ba}$ is more abundant compared to ${ }^{135} \mathrm{Ba}$, these values suggest that the detection limit of ${ }^{135} \mathrm{Cs}$ is either determined by the intrinsic ${ }^{135} \mathrm{Cs}$ content of commercial Csmaterials, by cross contamination in the ion source or by some yet unidentified interference at mass 135 . Nonetheless, studies of environmental ${ }^{135} \mathrm{Cs}-\mathrm{levels}$ are now feasible and being conducted.

\section{In-Depth Investigation Stage}

These isotopes have been investigated with ILIAMS, but further research work is required before full AMS measurements with environmental samples are feasible.

${ }^{41} \mathrm{Ca}$

AMS of ${ }^{41} \mathrm{Ca}\left(\mathrm{T}_{1 / 2}=1.03 \times 10^{5}\right.$ a) for both cosmogenic and medical applications suffers from interference of ${ }^{41} \mathrm{~K}$. The ion species of choice is $\mathrm{CaF}_{3}{ }^{-}$due to the hassle involved in chemical preparation and handling of $\mathrm{CaH}_{2}$ despite better AMS performance of the latter (Wallner et al. 2010). ISA-results demonstrated that suppression of $\mathrm{KF}_{3}^{-}$vs. $\mathrm{CaF}_{3}{ }^{-}$is possible inside ion guides (Zhao et al. 2016), despite that $\mathrm{KF}_{3}{ }^{-}$is a superhalogen anion with a calculated VDE of $6.83 \mathrm{eV}$ (Lo and Hopkinson 2011). The breakup into $\mathrm{KF}_{2}{ }^{-}$and $\mathrm{F}$ was identified as the main reaction channel with a theoretical threshold energy of $1.0 \mathrm{eV}$.

With ILIAMS, less than a factor of 10 suppression of $\mathrm{KF}_{3}{ }^{-}$is observed at $532 \mathrm{~nm}$, while $10 \mathrm{~W}$ of $355 \mathrm{~nm}$ laser yield suppression factors of up to $10^{4}$ at no laser-induced loss of ${ }^{41} \mathrm{Ca}$. Provided that the calculated VDE of $\mathrm{KF}_{3}^{-}$is correct within a factor of 2, this implies that photodetachment of the electron is energetically not possible and the observed removal of $\mathrm{KF}_{3}{ }^{-}$can only stem from dissociation processes. Calculated bond dissociation energies for the reaction channels $\mathrm{KF}_{3}^{-} \rightarrow \mathrm{KF}_{2}^{-}+\mathrm{F}, \mathrm{KF}_{3}^{-} \rightarrow \mathrm{KF}_{2}+\mathrm{F}^{-}$and $\mathrm{KF}_{3}^{-} \rightarrow \mathrm{KF}+\mathrm{F}_{2}^{-}$are all below $2.3 \mathrm{eV}$ (Lo and Hopkinson 2011). Which of these reaction pathways plays the dominant role and why it only becomes strongly enhanced in the presence of $3.49 \mathrm{eV}$ photons but not with $2.33 \mathrm{eV}$ photons remains to be investigated.

Sample spectra obtained on K-spiked blank material as well as SMD-Ca-10 reference material (Rugel et al. 2016) are shown in Figure 3. These were acquired by selecting the $4+$ charge state after the accelerator with a charge state yield at $3 \mathrm{MV}$ of $11 \%$ providing enough energy for further isobar suppression in the GIC. While there are still single ${ }^{41} \mathrm{~K}$ events visible from the K-spiked sample, the use of the $3+$ charge state with a yield of $22 \%$ or even lower charge states seems feasible and will be explored in the near future. This may partially compensate the present ion optical loss of $\sim 85 \%$ of $\mathrm{CaF}_{3}{ }^{-}$during injection into the ion guide, which is a consequence of the poor beam emittance from the source caused by the presence of $>50 \mu \mathrm{A}$ $\mathrm{F}^{-}$-current. Similar problems occur for most fluoride anions, but the ratio of $\mathrm{F}^{-}$to the species 

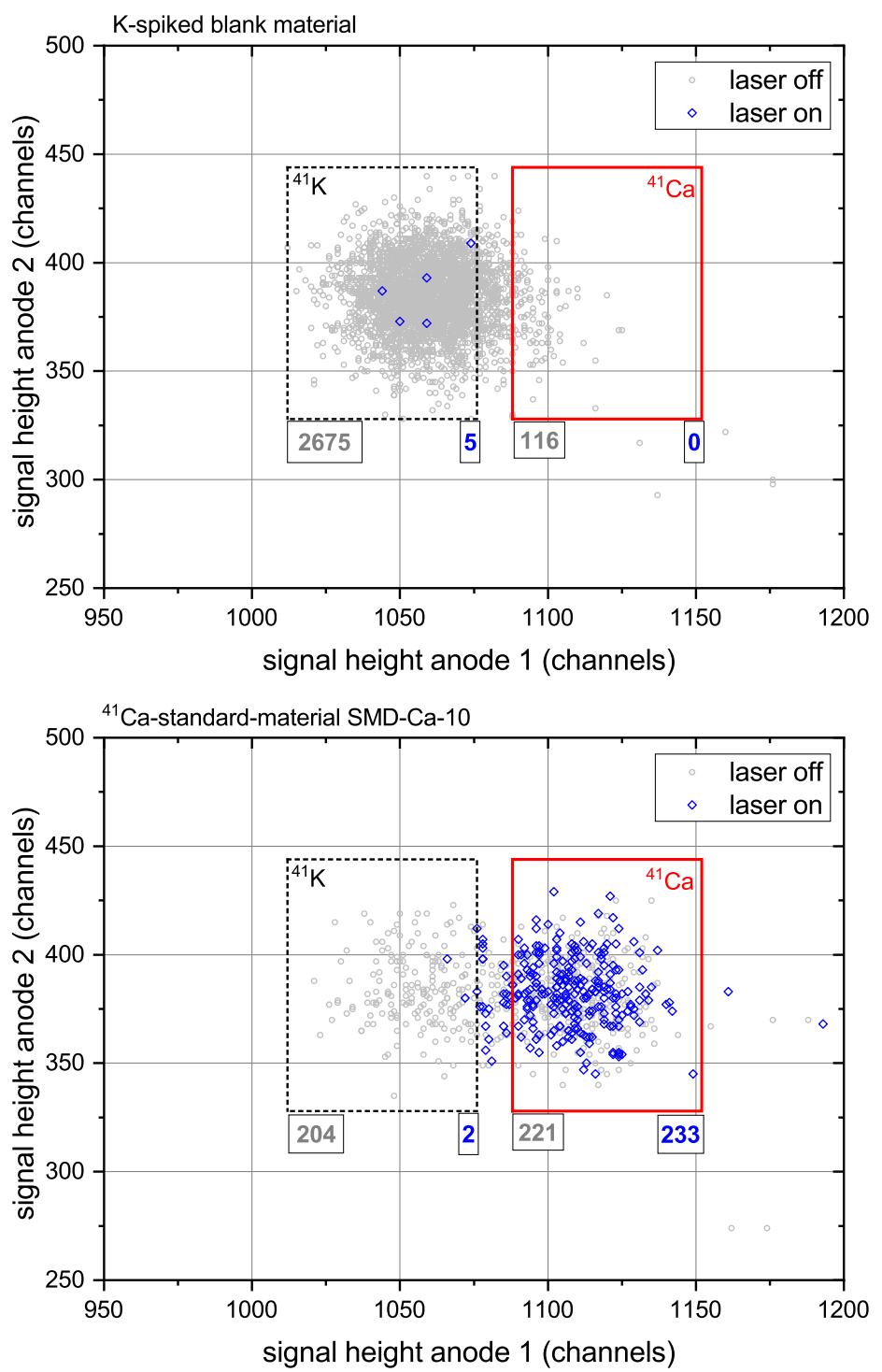

Figure 3 Sample spectra of ${ }^{41} \mathrm{Ca}^{4+}$ and ${ }^{41} \mathrm{~K}^{4+}$ acquired at $13.26 \mathrm{MeV}$ during an ILIAMS-beamtime. Gray events were collected without laser, events indicated as blue diamonds were collected with $1.5 \mathrm{~W}$ of $355 \mathrm{~nm}$ laser. The upper graph shows the energy loss spectra from commercial $\mathrm{CaF}_{2}$ material spiked with $\mathrm{KNO}_{3}$, the lower graph was collected on the reference material SMD-Ca-10 with a nominal ${ }^{41} \mathrm{Ca} /{ }^{40} \mathrm{Ca}$ ratio of $(0.9985 \pm 0.0054) \times 10^{-10}$ (Rugel et al. 2016). Regions of interest for ${ }^{41} \mathrm{Ca}$ and ${ }^{41} \mathrm{~K}$ are shown as rectangles; to the lower left corner the respective number of events within this $\mathrm{ROI}$ with laser off is given, and to the lower right, the number of events with laser on. Acquisition time was $100 \mathrm{~s}$ for all spectra. Despite running at reduced power, the laser light efficiently removes ${ }^{41} \mathrm{~K}$ while leaving ${ }^{41} \mathrm{Ca}$ intact.

of interest is exceptionally high in the case of $\mathrm{CaF}_{3}{ }^{-}$. Whether the observed $\mathrm{KF}_{3}{ }^{-}$-suppression can be enhanced to an extent that no subsequent isobar discrimination in the detector is required for environmental $\mathrm{Ca}$ samples remains open. The detection limit of ${ }^{41} \mathrm{Ca} / \mathrm{Ca}$ in the low $10^{-14}$ is currently set by the low overall detection efficiency rather than isobaric background. 
${ }^{99} \mathrm{Tc}$

Only two of the largest AMS facilities have so far succeeded in separating ${ }^{99} \mathrm{Tc}\left(\mathrm{T}_{1 / 2}=2.1 \times 10^{5} \mathrm{a}\right)$ from its abundant isobar ${ }^{99} \mathrm{Ru}$ to an extent that allows ${ }^{99} \mathrm{Tc}$-detection at levels of $10^{6}-10^{8}$ atoms per sample (Wacker et al. 2004; Koll et al. 2019). Since no stable isotope is available, AMS results either have to be normalized to another reference element, which bears the uncertainty of different negative ion yields and, in our case, ion guide transmissions and thus reduces precision to $\sim 30 \%$ when using $\mathrm{TcO}^{-}$, or each sample has to be spiked with known amounts of another Tc-isotope with reasonably long half-life, e.g., ${ }^{97} \mathrm{Tc}$. In the latter case, also Mo has to be suppressed as an additional isobar, which has hampered feasibility of this method so far.

ILIAMS development work for ${ }^{99} \mathrm{Tc}$ is tedious, as no measurable ion currents of this element are available, the VDEs of most molecular species are unknown and the atomic anions of the isobars have higher EAs than Tc (Andersen et al. 1999). At VERA, $\mathrm{TcF}_{5}{ }^{-}$has been experimentally identified as the most suitable anion exhibiting only $\sim 5 \%$ loss at $10 \mathrm{~W}$ of $532 \mathrm{~nm}$ laser light, while $\mathrm{RuF}_{5}{ }^{-}$is reduced by up to a factor $10^{5}$. This is surprising given a published $\mathrm{EA}_{\text {of }} \mathrm{RuF}_{5}{ }^{-}$of $5.2 \mathrm{eV}$ (Kuznetsov et al. 1989) and may indicate reaction pathways other than direct photodetachment of the surplus electron. Another advantage of this ion species is the intrinsic strong suppression of $\mathrm{RuF}_{5}{ }^{-}$observed when sputtering these ions from a $\mathrm{PbF}_{2}$-matrix enriched with $\mathrm{Nb}$ or Fe powder (Cornett et al. 2019). Preliminary results from a dilution series suggest that the ${ }^{99} \mathrm{Ru}$-induced background with ILIAMS results in a ${ }^{99}$ Tc-detection limit of $<10^{6}$ atoms for environmental samples. In the GIC, no discrimination between isobars is possible in the $3+$ or $4+$ charge state, and the ${ }^{99} \mathrm{Ru}$ signal has to be inferred from the count rate of ${ }^{101} \mathrm{Ru}$.

However, the problem of proper normalization remains unresolved as the suppression of $\mathrm{MoF}_{5}{ }^{-}$vs. $\mathrm{TcF}_{5}{ }^{-}$has proven more difficult. At $455 \mathrm{~nm}, \mathrm{MoF}_{5}{ }^{-}$is suppressed by $<2$ without observed effect on $\mathrm{TcF}_{5}{ }^{-}$while the $355 \mathrm{~nm}$ laser already induces more than $90 \%$ loss of $\mathrm{TcF}_{5}{ }^{-}$and suppresses $\mathrm{MoF}_{5}{ }^{-}$by (only) 100. This is insufficient for practical use as Mo is ubiquitous and the presently required amount of ${ }^{97} \mathrm{Tc}$ spike of $>10^{13}$ atoms per sample is not practical, because of production limitations, detector count rate issues and last but not least sample contamination risks caused by low but present levels of ${ }^{99} \mathrm{Tc}$ in the spike. Once a suitable way of normalizing the measured ${ }^{99} \mathrm{Tc}$ count rates is found, AMS of ${ }^{99} \mathrm{Tc}$ with ILIAMS should be straightforward independent of final ion energy.

\section{${ }^{182} \mathrm{Hf}$}

Attempts to measure ${ }^{182} \mathrm{Hf}$ of astrophysical origin at environmental concentrations with VERA have started early on but were hindered by isobaric background from ${ }^{182} \mathrm{~W}$ (Vockenhuber et al. 2004; Forstner et al. 2011). The status of ${ }^{182} \mathrm{Hf}$ AMS with ILIAMS has been recently summarized in (Martschini et al. 2020). Both $\mathrm{HfF}_{5}{ }^{-}$and its isobaric species $\mathrm{WF}_{5}{ }^{-}$are strongly bound anions and none of our lasers could induce any suppression. Experimental data suggest that UV lasers around $266 \mathrm{~nm}$ would be necessary (Leopold et al. 2014) and we envision this step in the future being aware that these high photon energies might cause unfavorable intense electron release from ion guide materials. However, we have succeeded in using our ion guide as a reaction cell by admixing $3 \% \mathrm{O}_{2}$ to the He buffer gas, which results in $10^{5}$ suppression of $\mathrm{WF}_{5}^{-}$at $\sim 25 \%$ loss of $\mathrm{HfF}_{5}^{-}$due to collisional detachment. This method had been suggested by (Zhao et al. 2013) and we have identified the adduct reaction $\mathrm{WF}_{5}{ }^{-} \rightarrow \mathrm{WF}_{5} \mathrm{O}^{-}$as the main reaction channel (Martschini et al. 2019). Following correction of the $\mathrm{W}$ contribution to the 182 -signal by monitoring the ${ }^{183} \mathrm{~W}$ count rate, blank values on commercial $\mathrm{HfF}_{4}$ (embedded in $\mathrm{PbF}_{2}$ matrix) of ${ }^{182} \mathrm{Hf} /{ }^{180} \mathrm{Hf}$ of $(3.4 \pm 2.1) \times 10^{-14}$ are achieved. The GIC provides no additional isobar separation with $3+$-ions such that similar 
detection limits should be within reach in lower charge states as well, provided that molecular background can be fully suppressed in the stripper medium.

\section{Early Exploration Stage}

With the following nuclides, only first tests have been conducted, mainly to identify suitable molecular anion species for ILIAMS. They will be discussed only briefly here but illustrate the huge potential of the method and hopefully bear good news in the near future.

\section{${ }^{32} \mathrm{Si}$}

In order to enable AMS detection of ${ }^{32} \mathrm{Si}$ other than at the largest tandem facilities (Morgenstern et al. 2010), several oxide molecules of Si have been investigated with ILIAMS regarding their potential for suppression of the ubiquitous isobar ${ }^{32} \mathrm{~S}$. Atomic EAs do not permit separation (Andersen et al. 1999) and the cross sections for suppression of $\mathrm{SiO}^{-}$, both by collisions as well as photodetachment, were found to be larger than for its isobar $\mathrm{SO}^{-}$. Thus, only $\mathrm{SiO}_{2}^{-}$and $\mathrm{SiO}_{3}{ }^{-}$can be considered as viable options. While the $532 \mathrm{~nm}$ laser destroys both $\mathrm{SiO}_{2}{ }^{-}$and $\mathrm{SO}_{2}{ }^{-}, \mathrm{SiO}_{3}{ }^{-}$experiences no losses compared to a factor $2-4$ reduction in transmitted $\mathrm{SO}_{3}{ }^{-}$ intensity. Higher photon energies may thus enhance separation of trioxides, unfortunately the $455 \mathrm{~nm}$ laser was not yet available during this study. At $355 \mathrm{~nm}$, all of the above anions are detached.

\section{${ }^{53} \mathrm{Mn}$}

Being of astrophysical and geological interest, ${ }^{53} \mathrm{Mn}$ is another entry on the "large-tandemsonly-list" as ample kinetic energy is required in AMS to separate the isobar ${ }^{53} \mathrm{Cr}$ in a gas-filledmagnet (Gladkis et al. 2007; Poutivtsev et al. 2010). Based on published EA data of $\mathrm{Mn}$ and $\mathrm{Cr}$ (Gutsev et al. 2000; Gutsev et al. 2001), the only anion species, which has reasonable ion yields from a $\mathrm{MnO}_{2}$ sputter matrix and is suited for ILIAMS, is $\mathrm{MnO}^{-}$, with an EA of $1.38 \mathrm{eV}$ compared to $1.22 \mathrm{eV}$ for $\mathrm{CrO}^{-}$. In a preliminary experiment, the transmission of $\mathrm{MnO}^{-}$ through the ion cooler was $38 \%$ and no reactions with pure He-gas or admixture of $\mathrm{O}_{2}$ were observed. $\mathrm{CrO}^{-}$showed similar behavior. Based on the EA values, a laser with a wavelength between $905 \mathrm{~nm}$ and $1017 \mathrm{~nm}$ will be required.

${ }^{60} \mathrm{Fe}$

AMS separation of the astrophysically relevant nuclide ${ }^{60} \mathrm{Fe}$ from its isobar ${ }^{60} \mathrm{Ni}$ is the picture book application of gas-filled magnets at large tandem facilities with detection limits of ${ }^{60} \mathrm{Fe} / \mathrm{Fe}$ below $10^{-16}$ (Ludwig et al. 2016; Wallner et al. 2016). Presently, ILIAMS cannot challenge these limits, as anion species combining proper EAs with high negative ion yield from a sputter source and good ion guide transmission have not been found yet. $\mathrm{FeO}^{-}$and $\mathrm{NiO}^{-}$differ only by $0.02 \mathrm{eV}$ in EA (Rienstra-Kiracofe et al. 2002), fluorides and hydrides generally suffer from low ion yields and strong parasitic currents from the ion source hampering ion guide transmissions. None of the molecular anions studied with ILIAMS so far allows the generation of intense ion beams for the AMS system. As soon as total detection efficiency is limiting the sensitivity, additional isobar suppression at AMS facilities with 6-8 MV is no solution. While this may not sound optimistic, the study is not yet completed and molecular systems still not crossed from the short list are $\mathrm{FeH}^{-}, \mathrm{FeF}_{3}{ }^{-}$and $\mathrm{FeF}_{4}{ }^{-}$.

${ }^{107} \mathrm{Pd}$

AMS of ${ }^{107} \mathrm{Pd}$ once was briefly attempted with a $14 \mathrm{MV}$-tandem but revealed insufficient suppression of the strong interference from the isobar ${ }^{107} \mathrm{Ag}$ (Korschinek et al. 1994). ILIAMS studies have identified $\mathrm{PdF}^{-}$as a likely suitable anion and possibly also $\mathrm{PdO}^{-}$and 
ruled out $\mathrm{PdO}_{2}^{-}$, which was found less stable than $\mathrm{AgO}_{2}{ }^{-}$. With $10 \mathrm{~W}$ of $532 \mathrm{~nm}$ laser light, $\mathrm{PdO}^{-}, \mathrm{AgO}^{-}$and $\mathrm{AgF}^{-}$are all depleted by $>99.9 \%$ while $\mathrm{PdF}^{-}$is only reduced by a factor of 3 , nourishing the expectation that this wavelength is close to the detachment threshold of $\mathrm{PdF}^{-}$ but well above that of $\mathrm{AgF}^{-}$. Further photodetachment studies with tunable lasers to find the optimum wavelength have been initiated.

\section{CONCLUSIONS AND OUTLOOK}

Over the past 5 years, ILIAMS has become a well-verified technique for isobar suppression and has significantly broadened the range of radionuclides accessible with medium-sized AMS facilities. It is now routinely applied for several isotopes at VERA and has been demonstrated to meet the requirements of AMS regarding reliability and robustness. One of the strengths of the method is its compatibility with, in principle, any subsequent AMS system; thus both compact facilities but also those with tandems $>5 \mathrm{MV}$ will profit. At least two other AMS facilities are currently developing new ILIAMS-setups and hopefully will soon contribute to this exciting field. The list of interesting candidates to explore with ILIAMS is long (cf. Figure 2). Once accessible at environmental levels, many of these isotopes will bring interesting new applications as was the case for e.g., ${ }^{236} \mathrm{U}$. Whether isobar separation with ILIAMS in this mass region is feasible, e.g., to measure ${ }^{236} \mathrm{Pu}$ and ${ }^{236} \mathrm{~Np}$ in the presence of ${ }^{236} \mathrm{U}$, will be explored within the scope of a recently awarded grant.

\section{ACKNOWLEDGMENTS}

Part of this work was funded by the RADIATE project under the Grant Agreement 824096 from the EU Research and Innovation program HORIZON 2020 and by grants Austrian Science Fund (FWF): P 22164-N20 and Austrian Science Fund (FWF): P 31614-N28. The authors acknowledge financial support of the ILIAMS research activities by "Investitionsprojekte" of the University of Vienna. We thank all students and technical staff involved, without their dedication ILIAMS would not have come beyond the planning stage. As physicists we feel indebted to Maki Honda from the Japan Atomic Energy Agency, Silke Merchel from HZDR Dresden and Francesca Quinto from KIT Karlsruhe for their continuous advice and effort in developing the sample preparation procedures required for new AMS isotopes. We are grateful to Dag Hanstorp and his team at Gothenburg University for fruitful collaboration and laser advice. The VERA-team thanks all users and colleagues, who agreed to provide samples for this work.

\section{REFERENCES}

Andersen T, Haugen H, Hotop H. 1999. Binding energies in atomic negative ions: III. Journal of Physical and Chemical Reference Data 28(6): 1511-1533.

Andersson P, Lindahl AO, Hanstorp D, Havener CC, Liu Y, Liu Y. 2010. Nearly complete isobar suppression by photodetachment. Journal of Applied Physics 107:026102.

Berkovits D, Boaretto E, Hollos G, Kutschera W, Naaman R, Paul M, Vager Z. 1989. Selective suppression of negative ions by lasers. Nuclear Instruments and Methods in Physics Research A 281:663-666.
Cheng SB, Berkdemir C, Melko JJ, Castleman AW. 2013. Probing the Electronic Structures and Relative Stabilities of Monomagnesium Oxide Clusters $\mathrm{MgO}_{\mathrm{x}}{ }^{-}$and $\mathrm{MgO}_{\mathrm{x}}(\mathrm{x}=1-4)$ : $\mathrm{A}$ Combined Photoelectron Imaging and Theoretical Investigation. Journal of Physical Chemistry A 117(46):11896-11905.

Collon P, Kutschera W, Loosli HH, Lehmann BE, Purtschert R, Love A, Sampson L, Anthony D, Cole D, Davids B, et al. 2000. ${ }^{81} \mathrm{Kr}$ in the Great Artesian Basin, Australia: a new method for dating very old groundwater. Earth Planetary Science Letters 182(1):103-113. 
Cornett RJ, Zhao XL, Hou XL, Kieser WE. 2019. A preliminary study of ${ }^{99} \mathrm{Tc}$ measurements using matrix-assisted low energy AMS. Nuclear Instruments and Methods in Physics Research B 455:181-189.

Eliades J, Litherland AE, Kieser WE, Cousins L, Ye $\mathrm{SJ}$, Zhao XL. 2010. Cl/S isobar separation using an on-line reaction cell for ${ }^{36} \mathrm{Cl}$ measurement at low energies. Nuclear Instruments and Methods in Physics Research B 268:839-842.

Eliades J, Zhao XL, Litherland AE, Kieser WE. 2013. On-line ion chemistry for the AMS analysis of ${ }^{90} \mathrm{Sr}$ and ${ }^{135,137} \mathrm{Cs}$. Nuclear Instruments and Methods in Physics Research B 294:361-363.

Eliades JA, Zhao XL, Litherland AE, Kieser WE. 2015. Negative ion-gas reaction studies using ion guides and accelerator mass spectrometry $\mathrm{I}$ : $\mathrm{SrF}_{3}^{-} \mathrm{YF}_{3}^{-} \mathrm{ZrF}_{3}^{-}, \mathrm{YF}_{4}^{-}$and $\mathrm{ZrF}_{5}^{-}$in $\mathrm{NO}_{2}$. Nuclear Instruments and Methods in Physics Research 361:294-299.

Forstner O, Michlmayr L, Auer M, Golser R, Kutschera W, Priller A, Steier P, Wallner A. 2008. Applications of a compact ionization chamber in AMS at energies below $1 \mathrm{MeV} /$ amu. Nuclear Instruments and Methods in Physics Research 266(10):2213-2216.

Forstner O, Gnaser H, Golser R, Hanstorp D, Martschini M, Priller A, Rohlén J, Steier P, Vockenhuber C, Wallner A. 2011. Reassessment of ${ }^{182} \mathrm{Hf}$ AMS measurements at VERA. Nuclear Instruments and Methods in Physics Research B 269:3180-3182.

Gladkis LG, Fifield LK, Morton CR, Barrows TT, Tims SG. 2007 Manganese-53: Development of the AMS technique for exposure-age dating applications. Nuclear Instruments and Methods in Physics Research B 259:236-240.

Gnaser H. 2007. Energy and angular distributions of sputtered species. Topics in Applied Physics 110:231-328.

Golser R, Kutschera W. 2017. Twenty years of VERA: toward a universal facility for accelerator mass spectrometry. Nuclear Physics News 27(3):29-34.

Gutsev GL, Rao BK, Jena P, Li X, Wang LS. 2000. Experimental and theoretical study of the photoelectron spectra of $\mathrm{MnO}_{\mathrm{x}}{ }^{-}(\mathrm{x}=1-3)$ clusters. Journal of Chemical Physics 113(4):1473-1483.

Gutsev GL, Jena P, Zhai HJ, Wang LS. 2001. Electronic structure of chromium oxides, $\mathrm{CrO}_{\mathrm{n}}{ }^{-}$ and $\mathrm{CrO}_{\mathrm{n}} \quad(\mathrm{n}=1-5)$ from photoelectron spectroscopy and density functional theory calculations. Journal of Chemical Physics 115(17):7935-7944.

Kilius LR, Zhao XL, Litherland AE, Purser KH. 1997. Molecular fragment problems in heavy element AMS. Nuclear Instruments and Methods in Physics Research B 123(1-4):10-17.

Koll D, Busser C, Faestermann T, Gómez-Guzmán JM, Hain K, Kinast A, Korschinek G, Krieg D, Lebert M, Ludwig P, Quinto F. 2019.
Recent developments for AMS at the Munich tandem accelerator. Nuclear Instruments and Methods in Physics Research B 438:180-183.

Korschinek G, Faestermann T, Kastel S, Knie K, Maier HJ, Fernandez-Niello J, Rothenberger M, Zerle L. 1994. AMS for M > 36 with a gasfilled magnetic spectrograph. Nuclear Instruments and Methods in Physics Research B 92:146-152

Kuznetsov SV, Korobov MV, Sidorov LN. 1989. Gas-phase negative ion chemistry of platinum metal fluorides iii negative ions of pentafluorides. International Journal Mass Spectrometry Ion Proc. 91(3):283-293.

Lachner J, Marek C, Martschini M, Priller A, Steier P, Golser R. 2019. ${ }^{36} \mathrm{Cl}$ in a new light: AMSmeasurements assisted by ion-laser interaction. Nuclear Instruments and Methods in Physics Research B 456:163-168.

Lachner J, Martschini M, Kalb A, Kern M, Marchhart O, Plasser F, Priller A, Steier P, Wieser A, Golser R. 2021. Highly sensitive ${ }^{26} \mathrm{Al}$ measurements by Ion-Laser-InterAction Mass Spectrometry. International Journal of Mass Spectrometry 465:116576.

Leopold T, Rohlén J, Andersson P, Diehl C, Eklund M, Forstner O, Hanstorp D, Hultgren H, Klason P, Lindahl AO, Wendt K. 2014. Feasibility of photodetachment isobar suppression of $\mathrm{WF}_{5}{ }^{-}$ with respect to $\mathrm{HfF}_{5}{ }^{-}$. International Journal of Mass Spectrometry 359:12-18.

Litherland AE, Tomski I, Zhao XL, Cousins LM, Doupé JP, Javahery G, Kieser WE. 2007. Isobar separation at very low energy for AMS. Nuclear Instruments and Methods in Physics Research B 259:230-235.

Liu Y, Beene JR, Havener CC, Liang JF. 2005. Isobar suppression by photodetachment in a gas-filled $\mathrm{rf}$ quadrupole ion guide. Applied Physics Letters 87:113504.

Lo S, Hopkinson AC. 2011. Superhalogen plus anion $\mathrm{KF}_{3}{ }^{-}$: A recently discovered anion with the formula $\mathrm{MX}_{\mathrm{k}+2^{-}}$. Computational and Theoretical Chemistry 973:9-12.

Ludwig P, Bishop S, Egli R, Chernenko V, Deneva B, Faestermann T, Famulok N, Fimiani L, GómezGuzmán JM, Hain K, et al. 2016. Time-resolved 2-million-year-old supernova activity discovered in Earth's microfossil record. Proceedings of the National Academy of Sciences 113(33):92329237.

MacDonald C, Charles CRJ, Cornett RJ, Zhao XL, Kieser WE, Litherland AE. 2014. Detection of ${ }^{135} \mathrm{Cs}$ by accelerator mass spectrometry. Rapid Communications in Mass Spectrometry 29: 115-118.

Martschini M, Pitters J, Moreau T, Andersson P, Forstner O, Hanstorp D, Lachner J, Liu Y, Priller A, Steier P, Golser R. 2017. Selective laser photodetachment of intense atomic and molecular negative ion beams with the ILIAS 
RFQ ion beam cooler. International Journal of Mass Spectrometry 415:9-17.

Martschini M, Hanstorp D, Lachner J, Marek C, Priller A, Steier P, Wasserburger P, Golser R. 2019. The ILIAMS project - an RFQ ion beam cooler for selective laser photodetachment at VERA. Nuclear Instruments and Methods in Physics Research B 456:213-217.

Martschini M, Lachner J, Merchel S, Priller A, Steier P, Wallner A, Wieser A, Golser R. 2020. The quest for AMS of ${ }^{182} \mathrm{Hf}$ - why poor gas gives pure beams. EPJ Web of Conferences 232:02003.

Martschini M, Marchhart O, Honda M, Lachner J, Priller A, Steier P, Wieser A, Golser R. In preparation. Utmost sensitivity in AMS of ${ }^{90} \mathrm{Sr}$ with Ion-Laser-Interaction Mass Spectrometry.

Maxeiner S, Synal HA, Christl M, Suter M, Müller A, Vockenhuber C. 2019. Proof of principle of a compact $300 \mathrm{kV}$ multi-isotope AMS facility. Nuclear Instruments and Methods in Physics Research B 439:84-89.

Morgenstern U, Fifield LK, Tims SG, Ditchburn RG. 2010. Progress in AMS measurement of natural ${ }^{32} \mathrm{Si}$ for glacier ice dating. Nuclear Instruments and Methods in Physics Research B 268:739-43.

Poutivtsev M, Dillmann I, Faestermann T, Knie K, Korschinek G, Lachner J, Meier A, Rugel G, Wallner A. 2010. Highly sensitive AMS measurements of ${ }^{53} \mathrm{Mn}$. Nuclear Instruments and Methods in Physics Research B 268:756-758.

Raisbeck GM, Yiou F, Peghaire A, Guillot J, Uzureau J. 1981. Instability of $\mathrm{KH}^{-}$and potential implications for detection of ${ }^{41} \mathrm{Ca}$ with a tandem electrostatic accelerator. Proceedings Symposium on accelerator mass spectrometry, Argonne, May 11-13 1981:426-430.

Rienstra-Kiracofe JC, Tschumper GS, Schaefer HF, Nandi S and Ellison GB. 2002. Atomic and molecular electron affinities: photoelectron experiments and theoretical computations. Chemical Reviews 102:231-282.

Rugel G, Pavetich S, Akhmadaliev S, Enamorado Baez SM, Scharf A, Ziegenrücker R, Merchel S. 2016. The first four years of the AMS-facility DREAMS: Status and developments for more accurate radionuclide data. Nuclear Instruments and Methods in Physics Research B 370:94-100.

Sasa K, Honda M, Hosoya S, Takahashi T, Takano K, Ochiai Y, Sakaguchi A, Kurita S, Satou Y, Sueki
K. 2021. A sensitive method for Sr-90 analysis by accelerator mass spectrometry. Journal of Nuclear Science Technology 58(1):72-79.

Schulze-König T, Seiler M, Suter M, Wacker L, Synal HA. 2011. The dissociation of ${ }^{13} \mathrm{CH}^{-}$and ${ }^{12} \mathrm{CH}_{2}{ }^{-}$ molecules in $\mathrm{He}$ and $\mathrm{N}_{2}$ at beam energies of $80-250$ $\mathrm{keV}$ and possible implications for radiocarbon mass spectrometry. Nuclear Instruments and Methods in Physics Research B 269:34-39.

Steier P, Golser R, Kutschera W, Priller A, Vockenhuber C, Winkler S. 2004. VERA, an AMS-facility for "all" isotopes. Nuclear Instruments and Methods in Physics Research B 223-224:67-71.

Synal HA. 2013. Developments in accelerator mass spectrometry. International Journal of Mass Spectrometry 349-350:192-202.

Tumey SJ, Brown TA, Hamilton TF, Hillegonds DJ. 2009. Further development of accelerator mass spectrometry for the measurement of ${ }^{90} \mathrm{Sr}$ at Lawrence Livermore National Laboratory. Journal of Radioanalytical and Nuclear Chemistry 282:821-824.

Vockenhuber C, Bichler M, Golser R, Kutschera W, Priller A, Steier S, Winkler S. 2004. ${ }^{182} \mathrm{Hf}$, a new isotope for AMS. Nuclear Instruments and Methods in Physics Research B 223224:823-828.

Wacker L, Fifield LK, Tims SG. 2004. Developments in AMS of ${ }^{99} \mathrm{Tc}$. Nuclear Instruments and Methods in Physics Research B 223-224:185-189.

Wallner A, Forstner O, Golser R, Korschinek G, Kutschera W, Priller A, Steier P, Vockenhuber C. 2010. Fluorides or hydrides? ${ }^{41} \mathrm{Ca}$ performance at VERA's 3-MV AMS facility. Nuclear Instruments and Methods in Physics Research B 268:799-803.

Wallner A, Feige J, Kinoshita N, Paul M, Fifield LK, Golser R, Honda M, Linnemann U, Matsuzaki H, Merchel S, et al. 2016. Recent near-Earth supernova probed by global deposition of interstellar radioactive ${ }^{60} \mathrm{Fe}$. Nature 532:69-72.

Zhao XL, Eliades J, Litherland AE, Kieser WE, Cornett J, Charles CRJ. 2013. On-line $\mathrm{HfF}_{5}{ }^{-} /$ $\mathrm{WF}_{5}{ }^{-}$separation in an $\mathrm{O}_{2}$-filled radiofrequency quadrupole gas cell. Rapid Communications in Mass Spectrometry 27:2818-2822.

Zhao XL, Litherland AE, Eliades J, Fu, YC, Kieser WE. 2016. A Study of $\mathrm{KF}_{3}^{-}$attenuation in an RFQ gas cell for ${ }^{41} \mathrm{Ca}$ AMS. Radiocarbon 55(2):268-281. 